\title{
Integrating dark diversity and functional traits to enhance nature conservation of epiphytic lichens: a case study from Northern Italy
}

\author{
Diego Pires Ferraz Trindade ${ }^{1} \cdot$ Meelis Pärtel $^{1}$. Carlos Pérez Carmona ${ }^{1}$. \\ Tiina Randlane ${ }^{1}$. Juri Nascimbene ${ }^{2}$
}

Received: 19 June 2020 / Revised: 8 April 2021 / Accepted: 24 May 2021 /

Published online: 29 May 2021

(C) The Author(s) 2021

\begin{abstract}
Mountains provide a timely opportunity to examine the potential effects of climate change on biodiversity. However, nature conservation in mountain areas have mostly focused on the observed part of biodiversity, not revealing the suitable but absent species-dark diversity. Dark diversity allows calculating the community completeness, indicating whether sites should be restored (low completeness) or conserved (high completeness). Functional traits can be added, showing what groups should be focused on. Here we assessed changes in taxonomic and functional observed and dark diversity of epiphytic lichens along elevational transects in Northern Italy spruce forests. Eight transects (900-1900 m) were selected, resulting in 48 plots and 240 trees, in which lichens were sampled using four quadrats per tree $(10 \times 50 \mathrm{~cm})$. Dark diversity was estimated based on species co-occurrence (Beals index). We considered functional traits related to growth form, photobiont type and reproductive strategy. Linear and Dirichlet regressions were used to examine changes in taxonomic metrics and functional traits along gradient. Our results showed that all taxonomic metrics increased with elevation and functional traits of lichens differed between observed and dark diversity. At low elevations, due to low completeness and harsh conditions, both restoration and conservation activities are needed, focusing on crustose species. Towards high elevations, conservation is more important to prevent species pool losses, focusing on macrolichens, lichens with Trentepohlia and sexual reproduction. Finally, dark diversity and functional traits provide a novel tool to enhance nature conservation, indicating particular threatened groups, creating windows of opportunities to protect species from both local and regional extinctions.
\end{abstract}

Keywords Biodiversity conservation $\cdot$ Climate change $\cdot$ Crustose $\cdot$ Functional diversity Macrolichens $\cdot$ Species pool

Communicated by Pradeep Kumar Divakar.

Juri Nascimbene

juri.nascimbene@unibo.it

Extended author information available on the last page of the article 


\section{Introduction}

Biodiversity conservation has to consider its multi-scale hierarchical nature, where species richness at macro scales (e.g. biogeographic patterns) delimits richness at finer scales, such as regional landscapes or local habitats (Noss 1990). As a consequence, the exploration of the mechanisms underpinning diversity patterns is often a tricky task due to the complex interplay between ecological and biogeographical-historical factors. In this perspective, mountain environments provide unique study areas where major environmental gradients co-vary with elevation over a relatively short distance and, thus, offer a natural tool allowing ecologists to explore the mechanisms that generate biodiversity and that rule species sorting into local communities (Körner 2007). Due to the strong climate-elevation relationship, elevational gradients are increasingly addressed as suitable models for predicting the potential effects of climate change on biodiversity and refine conservation and mitigation measures (McCain and Grytnes 2010; Nascimbene and Spitale 2017).

Traditionally, biodiversity conservation has taken into account how locally observed species richness (alpha-diversity) varies with changing conditions. However, such observed biodiversity measures do not reveal how many suitable species are absent from a local site (i.e., how complete communities are), defined as "dark diversity" (Pärtel et al. 2011). Specifically, dark diversity encompasses the set of species currently absent but able to colonize and establish in a given local site. By comparing the set of species in observed and dark diversity and its functional composition it is possible to understand why some species are absent, as well as to detect the relative importance of both environmental filtering and biotic interactions during the assembly process (de Bello et al. 2012; Riibak et al. 2015; Moeslund et al. 2017). Likewise, having both observed and dark diversity information allows looking at how much of the species pool is locally realized (community completeness; Pärtel et al. 2013), providing important information to guide both restoration and conservation actions (Lewis et al. 2017; Ronk et al. 2017; Boussarie et al. 2018). For example, local sites showing low community completeness may indicate that restoration activities are necessary, since the site is missing several potential species. On the other hand, sites with high community completeness might deserve high conservation priority, since these sites have less candidate species to substitute any local extinction (Lewis et al. 2017; Boussarie et al. 2018). If this information is linked to the functional traits of species, restoration or conservation actions can be more efficiently focused on specific ecological groups. For example, if species with low dispersal ability are those more often found in dark diversity, restoration activities can focus on increase connectivity between sites (i.e. landscape corridors) to facilitate colonization (Török and Helm 2017). Therefore, examining how observed and dark diversity change along environmental gradients can improve our understanding on both community assembly and conservation status of ecological communities.

Epiphytic lichens are an important component of forest biodiversity (Will-Wolf et al. 2002; Ellis 2012) and strongly contribute to ecosystem functioning (Cornelissen et al. 2007). They are obligate symbiotic organisms, composed of two or more symbionts, the fungal partner and the algal or cyanobacterial photosynthetic partner (Spribille et al. 2016). This symbiotic nature is a unique feature limiting their dispersal and local establishment, and therefore, also their diversity (Tripp et al. 2016). Furthermore, lichens as poikilohydric organisms are sensitive to both moisture availability and temperature changes, and thus they are among the most climate-sensitive organisms (Matos et al. 2015; Nascimbene and Marini 2015; Rubio-Salcedo et al. 2017). Recent studies have been indicating that their response to climate is likely mediated by species functional traits such as thallus growth 
form, photobiont type, and reproduction strategy reflecting their adaptation to desiccation, and the capability to disperse and establish under different environmental conditions (Ellis and Coppins 2006; Lewis and Ellis 2010; Giordani et al. 2016, 2019; Malíček et al. 2019). For example, crustose lichen species are considered more tolerant to drought whereas foliose and fruticose growth forms are less tolerant (Larson 1981). Likewise, lichens with different reproduction strategies contribute to different aspects in the tradeoff between dispersal and establishment, as sexual species usually disperse over longer distances but depend on the availability of a suitable photobiont at the settled location to establish, whereas asexual species have usually heavier diaspores dispersing closer while they do not depend on such association (Yahr et al. 2006; Belinchón et al. 2015; Morando et al. 2019). These specificities suggest that lichen diversity patterns are related to specific functional traits combinations that may vary along environmental gradients. However, whether or not these combinations differ between observed and dark diversity is currently unexplored for lichens, hindering to fully understand the mechanisms that determine how much of the species pool size is actually realized in a community and to hypothesize which species may be expected to contribute to community composition under changing climate. Therefore, combining community completeness information with functional traits may enhance the effectiveness of restoration and conservation measures to mitigate the impact of global change on epiphytic lichens. For example, in case the community completeness is low in certain sites and more dispersal limited species are found in dark diversity, restoration activities are needed focusing on species with low dispersal capacity. On the other hand, if the community completeness of lichens is high and the majority of species found in dark diversity are those low stress tolerant species, conservation strategies are more important focusing on managing microclimatic conditions, increasing the likelihood of establishment of low stress tolerant species and preventing their regional extinction.

Here we used a carefully collected data set (Nascimbene and Marini 2015), and examined the variation in number of species and functional composition of epiphytic lichen communities both in observed and dark diversity in several sites along the whole elevational gradient of spruce forests in northern Italy. We calculated the community completeness index to understand how much of the local species pool is realized along the gradient. Due to the sensitiveness of forest epiphytic lichens to increasing temperature and decreasing moisture (Ellis et al. 2007) we expect that observed diversity, dark diversity and community completeness will increase along our elevational gradient, but in different rates. We also hypothesize contrasting patterns of species functional traits between observed and dark diversity, increasing in magnitude along the elevational gradient, and reflecting the fact that dark diversity is composed mostly by those dispersal limited and lower stresstolerant species.

\section{Methods}

\section{Study area}

The study was carried out in North Italy, in the alpine region of South Tyrol where mean annual temperature ranges between $11-12{ }^{\circ} \mathrm{C}$ in the bottom of the main valley (Adige valley) and $2-3{ }^{\circ} \mathrm{C}$ above $1700 \mathrm{~m}$ a.s.l. In the driest part of the study area (Venosta Valley) annual precipitation does not exceed $600 \mathrm{~mm}$, while in the wettest areas (e.g. the Dolomites) annual precipitation reaches $1400 \mathrm{~mm}$. The bedrock is heterogeneous, including 
hard siliceous to metamorphic, porphyric and carbonatic rocks. Soils are mainly podsols and rendzinas. Spruce forests dominate the landscape between 900 and $1900 \mathrm{~m}$ a.s.l. representing $52 \%$ of the total forest cover. These forests are mainly managed with progressive thinning and exploitation of mature trees, both in even-aged or multilayered, uneven-aged stands.

\section{Sampling}

The regional forest database was used to select eight elevational transects spanning the full elevational range of spruce forests (900-1900 $\mathrm{m}$ a.s.1.) and the precipitation gradient of the region. Along each gradient, two stands with mature trees (one in even-aged and one in uneven aged formations) were selected at three elevational steps: $900-1200 \mathrm{~m}$; $1400-1600 \mathrm{~m} ; 1800-1900 \mathrm{~m}$. In each stand, a circular plot (13 m radius) was randomly placed and in each plot five mature spruce trees were randomly selected for lichen sampling. This resulted in 48 plots and 240 trees surveyed. On each tree, four $10 \mathrm{~cm} \times 50 \mathrm{~cm}$ frames divided in five $10 \mathrm{~cm} \times 10 \mathrm{~cm}$ quadrats were affixed at the four cardinal points with the shorter lower side at $100 \mathrm{~cm}$ from the ground (Asta et al. 2002). Two additional frames were affixed at the base of the tree trunk at North and South cardinal points. In each frame, the frequency of all the lichen species was recorded as the number of the quadrats in which they occurred. Species that were not identified in the field were all collected and checked in laboratory. For more details on sampling procedure and species identification see Nascimbene and Marini (2015).

\section{Dark diversity, species pool size and community completeness}

Dark diversity was estimated using the co-occurrence matrix of species, using the Beals method (see Lewis et al. (2016) for details). This procedure assigns species to local dark diversity based on how often they co-occur with the species that are actually present in the sampling site. The probabilities predicted by the Beals method are dependent on the frequency of the species in the dataset. This dependence can be corrected by applying species-specific probability thresholds, which effectively turns the index to binary. The Beals index can be calculated for all species for all sites and the threshold is based on probabilities from these sites where the species was actually found. To account for possible outliers in probabilities we used the $1 \%$ quantile as the threshold (Lewis et al. 2016). A species is considered in dark diversity only in sites where it is absent but the probability is greater than the species-specific threshold. Species pool size was calculated for each plot as the sum of observed and dark diversity. The community completeness index was calculated for each plot as: $\ln$ (observed richness/dark diversity) (Pärtel et al. 2013). This index allows to understand how much of the species pool size is actually realized in a community. Positive values mean that observed diversity is greater than dark diversity, whereas negative values indicate the opposite.

\section{Functional traits}

We considered three most commonly used functional traits of lichens related to growth form, photobiont type and reproductive strategy of lichens (Table 1) that were retrieved from ITALIC 5.0 the online information system on Italian lichens (Nimis and Martellos 


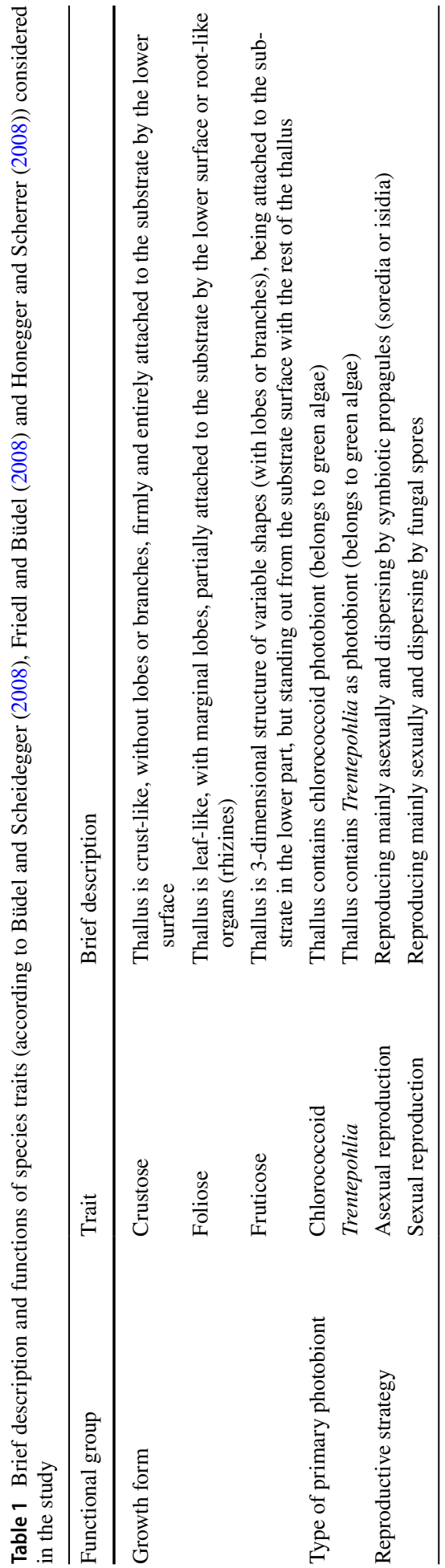


2017). The traits were selected based on the possible functional relation with the environmental gradients of interest. Growth form and photobiont type, for example, have known physiological relations with changes in forest light and humidity (Lakatos et al. 2006; Marini et al. 2011), while reproductive strategies are directly connected with lichen dispersal ability and establishment (Nascimbene and Spitale 2017). Each lichen species can belong only to a single category (trait value) in each of these traits. For example, regarding growth form, lichen species have either crustose, foliose or fruticose form. We calculated the proportion of each trait value in each site both for observed and dark diversities, considering presence-absence data.

\section{Data analysis}

We used linear regressions to test how observed and dark diversity, species pool size, and community completeness changed along the elevational gradient. Observed diversity, dark diversity and species pool size were log-transformed. Since elevation and temperature are highly correlated in our study (93\%-Appendix S4), we chose elevation as the predictor variable. Different linear models including basal area, tree circumference and rainfall as predictor variables were also considered but the simplest model (with elevation only) performed best according to Akaike information criterion (AIC) (Appendix S5). In addition, although we sampled both even-aged and uneven forest stands, we did not differentiate them in our model because both forests had rather similar environmental conditions (see Nascimbene and Marini (2015; Table 1)). To examine differences in trait value proportions between observed and dark diversity and to test whether these proportions change along the elevational gradient, we used linear Dirichlet regressions (Douma and Weedon 2019). This technique was selected since ordinary linear models are not fitting to analyse proportions. Dirichlet regressions were applied separately for all three traits (see Table 1). The models included diversity type (observed or dark diversity), elevation, and their interaction as predictors. Analyses were done with the DirichReg function of the R package "DirichletReg" (Maier 2020). To gain more information regarding the direction of patterns observed along the elevational gradient, we plotted predicted values with $95 \%$ confidence intervals generated from bootstrapping with 1000 randomizations (Douma and Weedon 2019).

We used the following $\mathrm{R}$ packages for data management, cleaning and visualization: dplyr (Wickham et al. 2020), purrr (Henry and Wickham 2020), broom (Robinson 2014), ggplot2 (Wickham 2016) and cowplot (Wilke 2020).

\section{Results}

Overall, 112 epiphytic lichen species were found along the eight elevational transects. From those, 88 were present in the dark diversity. The 24 species not found in the dark diversity were mostly those very rare (i.e. found in only one site), or very common: Chaenotheca trichialis and Parmeliopsis ambigua, both among the most frequent species in our study sites. The 10 most frequent species in observed and dark diversity as well as a list with all species found along the elevational transects are shown in Table 2 and Appendix S3, respectively. 
Table 2 The ten most frequent species of epiphytic lichens found in observed and dark diversity along an elevation gradient in spruce forests of northern Italy

\begin{tabular}{lll}
\hline Species & $\begin{array}{l}\text { Observed } \\
\text { diversity }\end{array}$ & Dark diversity \\
\hline Chaenotheca trichialis & 47 & 0 \\
Hypogymnia physodes & 39 & 1 \\
Vulpicida pinastri & 38 & 1 \\
Chaenotheca chrysocephala & 36 & 1 \\
Parmeliopsis ambigua & 34 & 0 \\
Chrysothrix candelaris & 33 & 6 \\
Parmeliopsis hyperopta & 33 & 1 \\
Parmelia sulcata & 28 & 6 \\
Tuckermannopsis chlorophylla & 28 & 6 \\
Buellia schaereri & 27 & 12 \\
Melanelixia fuliginosa & 27 & 12 \\
Ochrolechia microstictoides & 19 & 12 \\
Ochrolechia alboflavescens & 17 & 13 \\
Cladonia digitata & 16 & 13 \\
Biatora chrysantha & 14 & 17 \\
Cladonia coniocraea & 13 & 18 \\
Chaenothecopsis pusilla & 12 & 24 \\
Cladonia sp. & 11 & 18 \\
Opegrapha niveoatra & 8 & 12 \\
Lecanora expallens & 6 & 13 \\
\hline Nurs & &
\end{tabular}

Numbers depict how many times each species was found in observed and dark diversity, ordered by the most frequent in observed diversity

All lichen diversity metrics increased along the elevational gradient (Fig. 1; see statistics in Appendix S1): observed diversity $\left(R^{2}=0.75\right)$, dark diversity $\left(R^{2}=0.19\right)$, species pool size $\left(\mathrm{R}^{2}=0.80\right)$ and community completeness $\left(\mathrm{R}^{2}=0.15\right)$.

\section{Functional traits in observed and dark diversity along the elevational gradient}

Lichen species showed different functional patterns both among observed and dark diversity and along the elevational gradient, based on growth form, photobiont type and reproductive strategies (Fig. 2; see statistics in Appendix S2).

\section{Growth form}

Compared to observed diversity, species in dark diversity had higher proportions of crustose and fruticose forms and a lower proportion of foliose forms. Along the elevational gradient, there was an overall increase in foliose and fruticose forms, but no change in crustose form proportion. On the other hand, when the interaction was considered, crustose form proportion decreased more in dark than in observed diversity along the elevation transects. The foliose form proportion was lower in dark diversity along the entire gradient. The fruticose form proportion was lower in dark than in observed diversity at lower elevations, but higher at higher elevations (Fig. 2a). 
Fig. 1 Observed diversity, dark diversity and species pool size (a) and community completeness index (b) of epiphytic lichens along an elevation gradient in spruce forests of northern Italy (see Appendix S1 for details). Regression lines fitted by applying a linear regression. Shaded areas depict $95 \%$ confidence intervals
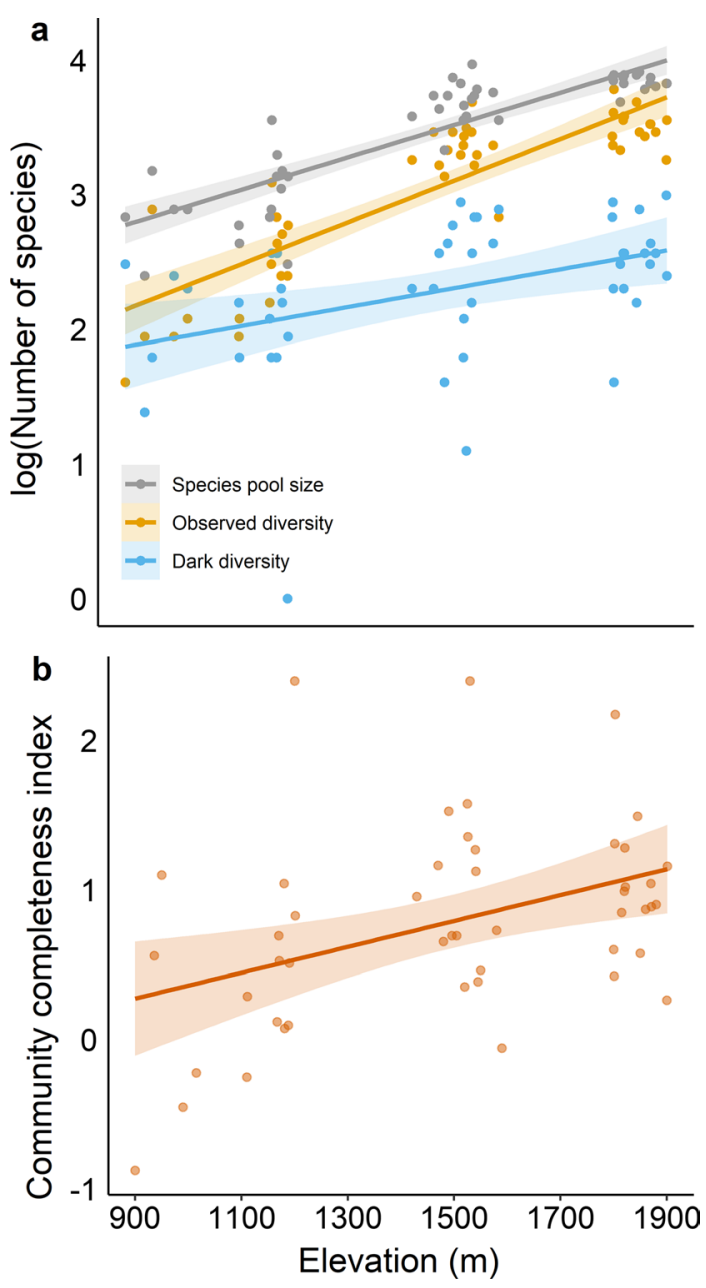

\section{Photobiont type}

Compared to observed diversity, species in dark diversity presented higher proportions of green algae but the proportion of Trentepohlia did not change. Along the elevational gradient there was an overall increase in the proportion of the green algae type, but no change in the proportion of Trentepohlia. When the interaction was considered, variation in the proportions of photobiont types in observed and dark diversity was not significantly different along the elevational gradient (Fig. 2b).

\section{Reproductive strategy}

Compared to observed diversity, species in dark diversity had a lower proportion of asexual and a higher proportion of sexual reproductive strategy. Along the elevational gradient, there was an overall increase in the proportion of asexual reproductive strategy in expense of the sexual one. There was no difference in the variation in the proportions 

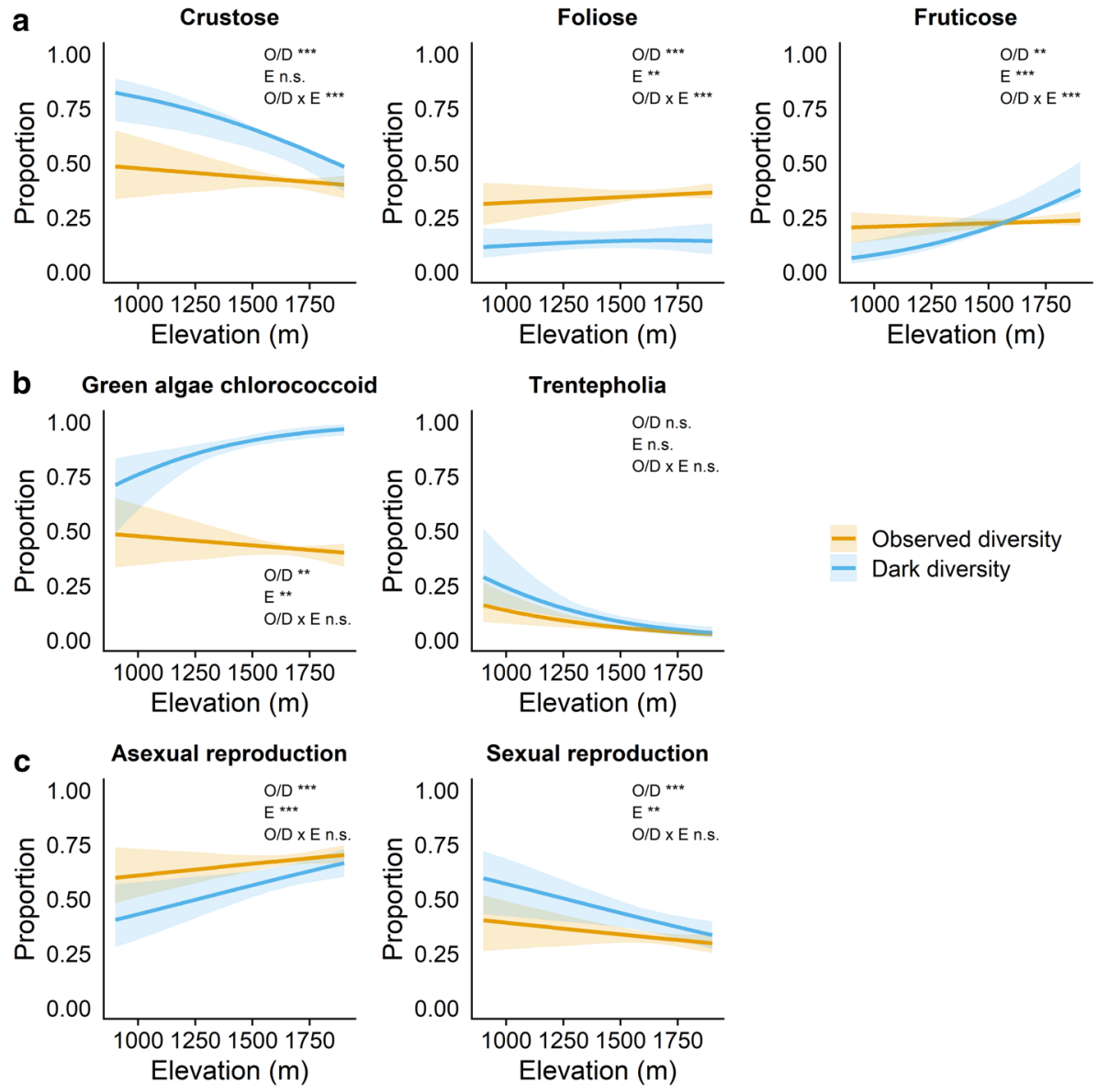

Fig. 2 Change in proportion of functional traits of epiphytic lichens in observed and dark diversity along an elevational gradient in spruce forests of Northern Italy. Solid lines depict mean predicted values from the bootstrapping (1000 randomizations) Dirichlet regression models, whereas shaded areas depict the confidence intervals (lower $=0.025$, upper $=0.975$ ). Annotations in panels inform whether the models are significant $(* \mathrm{p}<0.05, * * \mathrm{p}<0.01, * * * \mathrm{p}<0.001)$ or non-significant (n.s. $\mathrm{p} \geq 0.05)$ among observed and dark diversity (O/D); along the elevation (E); and their interaction (O/D x E). Details about the models are in Appendix S2

of reproductive strategies in observed and dark diversity along the elevational gradient (Fig. 2c).

\section{Discussion}

Linking patterns of observed and dark diversity with functional traits of species provides a novel tool for improving lichen conservation under a climate change scenario. Our results show that observed diversity, dark diversity, species pool size, and community completeness of epiphytic lichen communities increase along the elevational gradient, likely 
reflecting the sensitiveness of these organisms to temperature warming and decreasing moisture. However, observed diversity increases faster than dark diversity, revealing the added value of dark diversity when examining biodiversity trends. We also found contrasting patterns of species functional traits between observed and dark diversity, increasing in magnitude along the elevational gradient, but not always represented by higher proportion of lower stress-tolerant species in dark diversity. Despite that, these contrasting patterns reveal what groups of lichens should be prioritized in both conservation and restoration activities, highlighting the importance of considering functional composition of species in both observed and dark diversity.

The increase of species pool size and community completeness with elevation highlights important implications to conservation of epiphytic lichens. First, small species pool size and low completeness at lower elevations suggest that warmer environments impose stronger filters to epiphytic lichens, where only a subset of the species in the region are able to overcome these filters and be part of the local species pool, which is in agreement with other studies (Nascimbene and Marini 2015; Bässler et al. 2016). Second, as community completeness is lower at low elevations, in the short-term, restoration practices could facilitate the colonization and establishment of species currently in dark diversity, thus increasing completeness. However, warming scenarios might impose important challenges to species at low elevations, since the filters are already stronger and the species pool size is small, suggesting that long-term conservation strategies should focus on the entire species pool to prevent species losses in both observed and dark diversity (Trindade et al. 2020). Finally, the increasing difference between observed and dark diversity along the elevational gradient suggests that, under a warming scenario, observed diversity will likely decrease faster than dark diversity. Most of these locally extinct species will likely disappear from the local species pool (due to unsuitable conditions), reducing the chances of local recolonization. Previous studies have already shown that climate change will alter dramatically both local diversity and composition of lichen species (Escolar et al. 2012; Hauck et al. 2013) and that recolonization of lichens in restored sites might take several years (Johansson 2008). Therefore, due to proportionally lower dark diversity and an expected faster future species loss in the high elevation forests, preservation of the existing biodiversity should be the conservation priority in those areas. For example, conservation priority should focus on larger mountain forests, due to their capacity to harbor a larger number of epiphytic lichen species (Martellos et al. 2020), and on practicing non-intensive management of spruce forests in order to maintain microclimatic conditions, attenuating future macroclimatic changes and deaccelerating species loss (Nascimbene et al. 2014).

Examining taxonomic and functional traits in both observed and dark diversity along the elevational gradient provides a powerful tool to improve restoration and conservation activities, and to map threatened groups of epiphytic lichens under climate change. For example, higher proportion of crustose growth form, green algae photobiont type and sexual reproduction at lower elevations suggest that restoration activities should focus mostly on these groups of species, whereas the low proportion of macrolichens (fruticose and foliose) in dark diversity indicates that this group should be prioritized in conservation plans. Although crustose species are considered drought tolerant, their higher proportion in dark diversity at low elevations suggests that some establishment limitation occurs at those elevations, hampering some species of this group to thrive at warmer conditions. On the other hand, macrolichen species are expected to be highly threatened under climate change, either because they are more sensitive to warming (Boch et al. 2019) or due to their low proportion in dark diversity. This low stress-tolerance and low proportion in dark diversity indicates that local losses of macrolichens will likely represent species pool losses 
(i.e. species moving out of the species pool). Previous studies have already shown that macrolichens species are more likely to be lost from high towards low elevations (Nascimbene and Spitale 2017) and are more dispersal limited (Dettki et al. 2000), which increases even more their vulnerability.

Lichens present an interesting tradeoff between reproduction strategies and dispersal ability. On one hand, species with sexual reproduction (i.e. producing spores) disperse over longer distances, yet they depend on either the presence of a suitable photobiont at the new location to establish (Tehler 1982), an algal switch, i.e. the change of photobiont (Yahr et al. 2006; Nelsen and Gargas 2008) or fetching the alga from phylogenetically close asexual lichens (Belinchón et al. 2015). In contrast, asexual species have more difficulties to disperse, due to their heavier diaspores (Morando et al. 2019), but are more effective in establishing the new thalli because they already bear a suitable photobiont. This may allow simultaneously the development of abundant and viable populations resistant to extirpation and able to make moderate spatial shifts avoiding the risk of a mismatch between the mycobiont and the photobiont which would prevent re-synthesis of the lichen symbiosis. In this perspective, the higher proportion of species with sexual reproduction in dark diversity is in line with this win-win tradeoff and indicates that establishment limitation, not dispersal, could be more important for epiphytic lichens to cope with climate change (Komonen and Müller 2018). This is also consistent with the fact that sorediate (i.e. asexual) species generally have a wider distribution than their sexual counterparts (Mattsson and Lumbsch 1989; Randlane and Saag 2004; Mark et al. 2019), although their dispersal ability is lower. Our results also show that sexually reproducing species decrease with elevation in both observed and dark diversity, whereas asexual species increase. Therefore, conservation actions should pay primary attention to the species with sexual reproduction characteristics.

To conclude, our study highlights the potential of considering both observed and dark diversities to guide epiphytic lichen restoration and conservation activities under a climate change scenario, using elevational transects as a model. Our results suggest that epiphytic lichens are under threat due to climate change in both edges of the elevational gradient, but their extinction risk depends on a certain combination of traits. At low elevations both restoration and conservation activities are needed in order to increase community completeness, whereas towards high elevations conservation effort is more important to prevent an expected large number of species pool losses (i.e. species going extirpated from the species pool). From an applied context, at lower elevations, restoration should focus on crustose species, whereas towards higher elevations conservation priority should be given to macrolichens (foliose and fruticose), lichens with Trentepohlia association, and species with sexual reproduction strategy, either due to their lower proportion in dark diversity or higher sensitiveness to climate change. Finally, dark diversity and functional traits provide a novel tool to optimize restoration strategies, indicating particular groups we should focus on, and anticipate climate change effects, creating a window of opportunity to protect species from being both locally and regionally extinct.

Supplementary Information The online version contains supplementary material available at https://doi. org/10.1007/s10531-021-02211-w.

Acknowledgements We thank J.C. Douma for his comments on the Dirichlet regression models. The lichen survey was funded in the framework of the project "Biodiversità, biomonitoraggio e conservazione dei licheni epifiti negli ambienti forestali della provincia di Bolzano" by the Autonomous Province of Bolzano (Ripartizione Diritto allo Studio, Università e Ricerca Scientifica) to JN at the South Tyrol Museum of Natural History. 
Funding Open access funding provided by Alma Mater Studiorum - Università di Bologna within the CRUI-CARE Agreement. The lichen survey was funded in the framework of the project "Biodiversità, biomonitoraggio e conservazione dei licheni epifiti negli ambienti forestali della provincia di Bolzano" by the Autonomous Province of Bolzano (Ripartizione Diritto allo Studio, Università e Ricerca Scientifica) to JN at the South Tyrol Museum of Natural History. The study was financially supported by the Estonian Research Council (PRG609, PSG293 and PUT1017) and the European Regional Development Fund (Centre of Excellence EcolChange).

Data availability Data is available upon request.

\section{Declarations}

Conflict of interest The authors declare no conflict of interest.

Open Access This article is licensed under a Creative Commons Attribution 4.0 International License, which permits use, sharing, adaptation, distribution and reproduction in any medium or format, as long as you give appropriate credit to the original author(s) and the source, provide a link to the Creative Commons licence, and indicate if changes were made. The images or other third party material in this article are included in the article's Creative Commons licence, unless indicated otherwise in a credit line to the material. If material is not included in the article's Creative Commons licence and your intended use is not permitted by statutory regulation or exceeds the permitted use, you will need to obtain permission directly from the copyright holder. To view a copy of this licence, visit http://creativecommons.org/licenses/by/4.0/.

\section{References}

Asta J, Erhardt W, Ferretti M et al (2002) Mapping lichen diversity as an indicator of environmental quality. In: Nimis PL, Scheidegger C, Wolseley PA (eds) Monitoring with lichens monitoring lichens. Springer, Dordrecht, pp 273-279

Bässler C, Cadotte MW, Beudert B et al (2016) Contrasting patterns of lichen functional diversity and species richness across an elevation gradient. Ecography 39:689-698. https://doi.org/10.1111/ecog.01789

Belinchón R, Yahr R, Ellis CJ (2015) Interactions among species with contrasting dispersal modes explain distributions for epiphytic lichens. Ecography 38:762-768. https://doi.org/10.1111/ecog.01258

Boch S, Martins A, Ruas S et al (2019) Bryophyte and macrolichen diversity show contrasting elevation relationships and are negatively affected by disturbances in laurel forests of Madeira island. J Veg Sci 30:1122-1133. https://doi.org/10.1111/jvs.12802

Boussarie G, Bakker J, Wangensteen OS et al (2018) Environmental DNA illuminates the dark diversity of sharks. Sci Adv 4:eaap9661. https://doi.org/10.1126/sciadv.aap9661

Büdel B, Scheidegger C (2008) Thallus morphology and anatomy. In: Nash TH (ed) Lichen biology. Cambridge University Press, Cambridge, pp 40-68

Cornelissen JHC, Lang SI, Soudzilovskaia NA, During HJ (2007) Comparative cryptogam ecology: a review of bryophyte and lichen traits that drive biogeochemistry. Ann Bot 99:987-1001. https://doi. org/10.1093/aob/mcm030

de Bello F, Price JN, Münkemüller T et al (2012) Functional species pool framework to test for biotic effects on community assembly. Ecology 93:2263-2273. https://doi.org/10.1890/11-1394.1

Dettki H, Klintberg P, Esseen P-A (2000) Are epiphytic lichens in young forests limited by local dispersal? Écoscience 7:317-325. https://doi.org/10.1080/11956860.2000.11682601

Douma JC, Weedon JT (2019) Analysing continuous proportions in ecology and evolution: a practical introduction to beta and Dirichlet regression. Methods Ecol Evol 10:1412-1430. https://doi.org/10.1111/ 2041-210X.13234

Ellis CJ (2012) Lichen epiphyte diversity: a species, community and trait-based review. Perspect Plant Ecol Evol Syst 14:131-152. https://doi.org/10.1016/j.ppees.2011.10.001

Ellis CJ, Coppins BJ (2006) Contrasting functional traits maintain lichen epiphyte diversity in response to climate and autogenic succession. J Biogeogr 33:1643-1656. https://doi.org/10.1111/j.1365-2699. 2006.01522.x 
Ellis CJ, Coppins BJ, Dawson TP, Seaward MRD (2007) Response of British lichens to climate change scenarios: trends and uncertainties in the projected impact for contrasting biogeographic groups. Biol Conserv 140:217-235. https://doi.org/10.1016/j.biocon.2007.08.016

Escolar C, Martínez I, Bowker MA, Maestre FT (2012) Warming reduces the growth and diversity of biological soil crusts in a semi-arid environment: implications for ecosystem structure and functioning. Philos Trans R Soc B 367:3087-3099. https://doi.org/10.1098/rstb.2011.0344

Friedl T, Büdel B (2008) Photobionts. In: Nash TH (ed) Lichen biology. Cambridge University Press, Cambridge, pp 9-27

Giordani P, Malaspina P, Benesperi R et al (2019) Functional over-redundancy and vulnerability of lichen communities decouple across spatial scales and environmental severity. Sci Total Environ 666:22-30. https://doi.org/10.1016/j.scitotenv.2019.02.187

Giordani P, Rizzi G, Caselli A et al (2016) Fire affects the functional diversity of epilithic lichen communities. Fungal Ecol 20:49-55. https://doi.org/10.1016/j.funeco.2015.11.003

Hauck M, de Bruyn U, Leuschner C (2013) Dramatic diversity losses in epiphytic lichens in temperate broad-leaved forests during the last 150years. Biol Conserv 157:136-145. https://doi.org/10.1016/j. biocon.2012.06.015

Henry L, Wickham H (2020) purrr: Functional Programming Tools. R package version 0.3.4. https:// CRAN.R-project.org/package=purrr

Honegger R, Scherrer S (2008) Sexual reproduction in lichen-forming ascomycetes. In: Nash TH (ed) Lichen biology. Cambridge University Press, Cambridge, pp 94-103

Johansson P (2008) Consequences of disturbance on epiphytic lichens in boreal and near boreal forests. Biol Conserv 141:1933-1944. https://doi.org/10.1016/j.biocon.2008.05.013

Komonen A, Müller J (2018) Dispersal ecology of deadwood organisms and connectivity conservation. Conserv Biol 32:535-545. https://doi.org/10.1111/cobi.13087

Körner C (2007) The use of "altitude" in ecological research. Trends Ecol Evol 22:569-574. https://doi.org/ 10.1016/j.tree.2007.09.006

Lakatos M, Rascher U, Büdel B (2006) Functional characteristics of corticolous lichens in the understory of a tropical lowland rain forest. New Phytol 172:679-695. https://doi.org/10.1111/j.1469-8137.2006. 01871.x

Larson DW (1981) Differential wetting in some lichens and mosses: the role of morphology. The Bryologist 84:1. https://doi.org/10.2307/3242973

Lewis JEJ, Ellis CJ (2010) Taxon- compared with trait-based analysis of epiphytes, and the role of tree species and tree age in community composition. Plant Ecol Divers 3:203-210. https://doi.org/10.1080/ 17550874.2010 .505966

Lewis RJ, de Bello F, Bennett JA et al (2017) Applying the dark diversity concept to nature conservation. Conserv Biol 31:40-47. https://doi.org/10.1111/cobi.12723

Lewis RJ, Szava-Kovats R, Pärtel M (2016) Estimating dark diversity and species pools: an empirical assessment of two methods. Methods Ecol Evol 7:104-113. https://doi.org/10.1111/2041-210X.12443

Maier MJ (2020) DirichletReg: Dirichlet Regression in R. R package version 0.7-0. https://CRAN.R-project. org/package $=$ DirichletReg

Mark K, Randlane T, Thor G, Hur J, Obermayer W, Saag A (2019) Lichen chemistry is concordant with multilocus gene genealogy in the genus Cetrelia (Parmeliaceae, Ascomycota). Fungal Biol 123:125139. https://doi.org/10.1016/j.funbio.2018.11.013

Malíček J, Palice Z, Vondrák J et al (2019) Lichens in old-growth and managed mountain spruce forests in the Czech Republic: assessment of biodiversity, functional traits and bioindicators. Biodivers Conserv 28:3497-3528. https://doi.org/10.1007/s10531-019-01834-4

Marini L, Nascimbene J, Nimis PL (2011) Large-scale patterns of epiphytic lichen species richness: photobiont-dependent response to climate and forest structure. Sci Total Environ 409:4381-4386. https:// doi.org/10.1016/j.scitotenv.2011.07.010

Martellos S, d'Agostino M, Chiarucci A et al (2020) Lichen distribution patterns in the ecoregions of Italy. Diversity 12:294. https://doi.org/10.3390/d12080294

Matos P, Pinho P, Aragón G et al (2015) Lichen traits responding to aridity. J Ecol 103:451-458. https://doi. org/10.1111/1365-2745.12364

Mattsson J-E, Lumbsch HT (1989) The use of the species pair concept in lichen taxonomy. Taxon 38:238241. https://doi.org/10.2307/1220840

McCain CM, Grytnes JA (2010) Elevational gradients in species richness. In: McCain CM, Grytnes JA (eds) Encyclopedia of life sciences

Moeslund JE, Brunbjerg AK, Clausen KK et al (2017) Using dark diversity and plant characteristics to guide conservation and restoration. J Appl Ecol 54:1730-1741. https://doi.org/10.1111/1365-2664. 12867 
Morando M, Matteucci E, Nascimbene J et al (2019) Effectiveness of aerobiological dispersal and microenvironmental requirements together influence spatial colonization patterns of lichen species on the stone cultural heritage. Sci Total Environ 685:1066-1074. https://doi.org/10.1016/j.scitotenv.2019.06.238

Nascimbene J, Marini L (2015) Epiphytic lichen diversity along elevational gradients: biological traits reveal a complex response to water and energy. J Biogeogr 42:1222-1232. https://doi.org/10.1111/jbi. 12493

Nascimbene J, Nimis PL, Dainese M (2014) Epiphytic lichen conservation in the Italian Alps: the role of forest type. Fungal Ecol 11:164-172. https://doi.org/10.1016/j.funeco.2014.06.006

Nascimbene J, Spitale D (2017) Patterns of beta-diversity along elevational gradients inform epiphyte conservation in alpine forests under a climate change scenario. Biol Conserv 216:26-32. https://doi.org/ 10.1016/j.biocon.2017.09.021

Nelsen MP, Gargas A (2008) Dissociation and horizontal transmission of codispersing lichen symbionts in the genus Lepraria (Lecanorales: Stereocaulaceae). New Phytol 177:264-275. https://doi.org/10. 1111/j.1469-8137.2007.02241.x

Nimis PL, Martellos S (2017) ITALIC - The information system on Italian Lichens. Version 5.0. University of Trieste, Department of Biology. http://dryades.units.it/italic

Noss RF (1990) Indicators for monitoring biodiversity: a hierarchical approach. Conserv Biol 4:355-364

Pärtel M, Szava-Kovats R, Zobel M (2011) Dark diversity: shedding light on absent species. Trends Ecol Evol 26:124-128. https://doi.org/10.1016/j.tree.2010.12.004

Pärtel M, Szava-Kovats R, Zobel M (2013) Community completeness: linking local and dark diversity within the species pool concept. Folia Geobot 48:307-317. https://doi.org/10.1007/s12224-013-9169-X

Randlane T, Saag A (2004) Distribution patterns of some primary and secondary cetrarioid species. Symb Bot Ups 34(1):359-376

Riibak K, Reitalu T, Tamme R et al (2015) Dark diversity in dry calcareous grasslands is determined by dispersal ability and stress-tolerance. Ecography 38:713-721. https://doi.org/10.1111/ecog.01312

Robinson D (2014) broom: An R package for converting statistical analysis objects into tidy data frames. ArXiv Preprint ArXiv:1412.3565. https://cran.r-project.org/web/packages/broom/index.html

Ronk A, Szava-Kovats R, Zobel M, Pärtel M (2017) Observed and dark diversity of alien plant species in Europe: estimating future invasion risk. Biodivers Conserv 26:899-916. https://doi.org/10.1007/ s10531-016-1278-4

Rubio-Salcedo M, Psomas A, Prieto M et al (2017) Case study of the implications of climate change for lichen diversity and distributions. Biodivers Conserv 26:1121-1141. https://doi.org/10.1007/ s10531-016-1289-1

Spribille T, Tuovinen V, Resl P et al (2016) Basidiomycete yeasts in the cortex of ascomycete macrolichens. Science 353:488-492. https://doi.org/10.1126/science.aaf8287

Tehler A (1982) The species pair concept in lichenology. Taxon 31:708-714. https://doi.org/10.2307/12196 89

Török P, Helm A (2017) Ecological theory provides strong support for habitat restoration. Biol Conserv 206:85-91. https://doi.org/10.1016/j.biocon.2016.12.024

Trindade DPF, Carmona CP, Pärtel M (2020) Temporal lags in observed and dark diversity in the Anthropocene. Glob Change Biol 26:3193-3201. https://doi.org/10.1111/gcb.15093

Tripp EA, Lendemer JC, Barberán A et al (2016) Biodiversity gradients in obligate symbiotic organisms: exploring the diversity and traits of lichen propagules across the United States. J Biogeogr 43:16671678. https://doi.org/10.1111/jbi.12746

Wickham H (2016) ggplot2: elegant graphics for data analysis. Springer, New York

Wickham H, François R, Henry L, Müller K (2020) dplyr: a grammar of data manipulation. R package version 1.0.0. https://CRAN.R-project.org/package=dplyr

Wilke CO (2020) cowplot: Streamlined Plot Theme and Plot Annotations for 'ggplot2'. R package version 1.0.0.9000. https://CRAN.R-project.org/package=cowplot

Will-Wolf S, Esseen P-A, Neitlich P (2002) Monitoring biodiversity and ecosystem function: forests. In: Nimis PL, Scheidegger C, Wolseley PA (eds) Monitoring with lichens monitoring lichens. Springer, Dordrecht, pp 203-222

Yahr R, Vilgalys R, DePriest PT (2006) Geographic variation in algal partners of Cladonia subtenuis (Cladoniaceae) highlights the dynamic nature of a lichen symbiosis. New Phytol 171:847-860. https://doi. org/10.1111/j.1469-8137.2006.01792.x

Publisher's Note Springer Nature remains neutral with regard to jurisdictional claims in published maps and institutional affiliations. 


\section{Authors and Affiliations}

\section{Diego Pires Ferraz Trindade ${ }^{1} \cdot$ Meelis Pärtel $^{1} \cdot$ Carlos Pérez Carmona $^{1}$.} Tiina Randlane ${ }^{1}$. Juri Nascimbene ${ }^{2}$

1 Institute of Ecology and Earth Sciences, University of Tartu, Lai 40, 51005 Tartu, Estonia

2 BIOME Lab, Department of Biological Geological and Environmental Sciences, Alma Mater Studiorum - University of Bologna, Via Irnerio 42, 40126 Bologna, Italy 